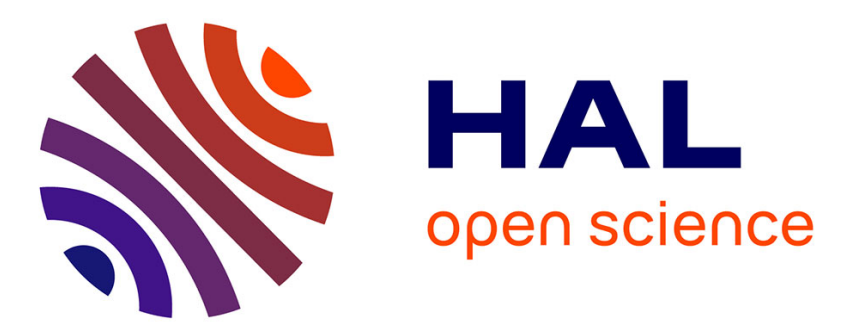

\title{
STEM and EDXS characterization of physico-chemical reactions at the periphery of bioactive glass particles in contact with biological fluids
}

\author{
Edouard Jallot, V. Blanchet, E. Chassot, L. Kilian, Y. Josset, D. \\ Laurent-Maquin
}

\section{To cite this version:}

Edouard Jallot, V. Blanchet, E. Chassot, L. Kilian, Y. Josset, et al.. STEM and EDXS characterization of physico-chemical reactions at the periphery of bioactive glass particles in contact with biological fluids. International Symposium on Trace Elements in Human: New Perspectives 4, Oct 2003, Athenes, Greece. pp.1295-1302. in2p3-00014095

\section{HAL Id: in2p3-00014095 \\ https://hal.in2p3.fr/in2p3-00014095}

Submitted on 3 Nov 2003

HAL is a multi-disciplinary open access archive for the deposit and dissemination of scientific research documents, whether they are published or not. The documents may come from teaching and research institutions in France or abroad, or from public or private research centers.
L'archive ouverte pluridisciplinaire HAL, est destinée au dépôt et à la diffusion de documents scientifiques de niveau recherche, publiés ou non, émanant des établissements d'enseignement et de recherche français ou étrangers, des laboratoires publics ou privés. 
STEM and EDXS characterisation of physico-chemical reactions at the periphery of bioactive glass particles in contact with biological fluids.

E. JALLOT ${ }^{1 *}$, V. BANCHET ${ }^{2}$, E. CHASSOT ${ }^{1}$, L. KILIAN² ${ }^{2}$, Y. JOSSET², D. LAURENTMAQUIN $^{2}$.

${ }^{1}$ Laboratoire de Physique Corpusculaire de Clermont-Ferrand CNRS/IN2P3 UMR 6533, 24 avenue des Landais, 63177 AUBIERE Cedex, France

2 INSERM ERM 0203, Laboratoire de Microscopie Electronique, 21 rue Clément Ader, 51685 REIMS Cedex 2, France

\section{* Corresponding author :}

Edouard JALLOT

Laboratoire de Physique Corpusculaire de Clermont-Ferrand CNRS/IN2P3 UMR 6533

Université Blaise Pascal - 24 avenue des Landais, 63177 Aubiere Cedex, France.

Tel : 33 (0)4 73407265

Fax : $33(0) 473264598$

E-mail : jallot@clermont.in2p3.fr 


\begin{abstract}
Knowledge of the local concentration and species of ions released at the bioactive glass particles/biological fluids interface is primordial to the understand of the complex interfacial reactions and physico-chemical properties of bioactive glasses. This work characterises the interface that bioactive glass particles develop after immersion into biological fluids for different delays (1, 2, 4, 28 days). The distribution of silicon, phosphorus, calcium and aluminium varied across bioactive particles periphery. After 1 day of immersion into biological fluids, a Si-Al rich layer appeared at the bioactive glass surface. After 2 days, significantly higher concentrations of $\mathrm{Ca}$ and $\mathrm{P}$ are observed on top of this newly formed SiAl layer compared to the center of the glass particles. Then, an apatite (Ca-P) layer starts to built up and grows with time after immersion into biological fluids. The $\mathrm{Ca} / \mathrm{P}$ atomic ratio increases with time from 1 to 1.6. A thick Ca-P rich layer was formed after 28 days. The Ca-P layer appeared to be generated by calcium and phosphate ions diffusing through the Si-Al layer, which contain at least traces of these ions.
\end{abstract}

Keywords : STEM - EDXS - bioactive glass - apatite - physico-chemical reactions - 


\section{Introduction}

In orthopaedic and dental applications, calcium phosphate based ceramics, glass ceramics and bioactive glasses have been used by virtue of their ability to bond directly with bone tissues and to promote bone formation ${ }^{1}$. This property has become known as bioactivity. Hench L.L. demonstrated this bioactive properties for certain glass composition ${ }^{2,3}$. Dynamic ion exchange and bonding to bone were demonstrated for a certain compositional range with $\mathrm{SiO}_{2}, \mathrm{Na}_{2} \mathrm{O}, \mathrm{CaO}$ and $\mathrm{P}_{2} \mathrm{O}_{5}$ in specific proportions ${ }^{4,5,6}$. But, the composition has to be optimised to give a suitable compromise between bioactivity and solubility ${ }^{7}$. For example, addition of $\mathrm{Al}_{2} \mathrm{O}_{3}$ may be used to control certain physical properties. By increasing the silica content and by adding alumina the solubility of the bioactive glass could be minimised ${ }^{8,9}$.

The studied bioactive glass is in the $\mathrm{SiO}_{2}-\mathrm{Na}_{2} \mathrm{O}-\mathrm{CaO}-\mathrm{P}_{2} \mathrm{O}_{5}-\mathrm{K}_{2} \mathrm{O}-\mathrm{Al}_{2} \mathrm{O}_{3}-\mathrm{MgO}$ system. In this work, the bioactive glass is under powder form. The objective of this paper is to understand surface and physico-chemical reactions at the periphery of bioactive glass particles that lead to bioactivity.

Knowledge of the elemental distribution at the bioactive glass periphery is important to understand the physico-chemical mechanisms during interactions with biological fluids ${ }^{10}$. Chemical evaluation of the bioactive glass/bone interface was performed by Scanning Transmission Electron Microscopy (STEM) associated to Energy Dispersive X-ray Spectroscopy (EDXS). Thus, our measurements and the discussion are focussed on Si, Ca, P and $\mathrm{Al}$ elements which are the most important during physico-chemical reactions at the bioactive material periphery. 


\section{Materials and Methods}

Bioactive glass particles characteristics

The bioactive glass composition is : $50 \% \mathrm{SiO}_{2}, 20 \% \mathrm{Na}_{2} \mathrm{O}, 16 \% \mathrm{CaO}, 6 \% \mathrm{P}_{2} \mathrm{O}_{5}, 5 \%$ $\mathrm{K}_{2} \mathrm{O}, 2 \% \mathrm{Al}_{2} \mathrm{O}_{3}$ and $1 \% \mathrm{MgO}$ (\% weight). The bioactive glass was obtained by melting a mixture of raw materials in a platinum crucible at high temperature ( 2 hours at $1200^{\circ} \mathrm{C}$ and 3 hours at $\left.1350^{\circ} \mathrm{C}\right)$. Then, the glass was cast, crushed and transformed into powder of grain size under $40 \mu \mathrm{m}$ in diameter. After production, the glass composition was determined by Atomic Emission Spectrometry and its crystallinity was evaluated by X-rays diffraction.

\section{Sample treatment}

The glass powder ( $2 \mathrm{mg}$ ) was immersed at $37^{\circ} \mathrm{C}$ for $1,2,4$ and 28 days in $1 \mathrm{ml}$ of a standard Dulbecco’s Modified Eagle Medium (DMEM, Gibco, Cergy Pontoise, France) (pH : 7.3). DMEM contained the following ingredients (mg/l): $6400 \mathrm{NaCl}, 400 \mathrm{KCl}, 200 \mathrm{CaCl}_{2}$, $200 \mathrm{MgSO}_{4}-7 \mathrm{H}_{2} \mathrm{O}, 124 \mathrm{NaH}_{2} \mathrm{PO}_{4}, 3700 \mathrm{NaHCO}_{3}$.

Specimens preparation and $X$-ray microanalysis

After treatment the glass powder was lying on the bottom of the box. The medium was carefully removed with a pipette. Then the bioactive glass powder is embedded in resin (AGAR, Essex, England). Thin sections of 100 nanometers nominal thickness are prepared by means of a FC 4E Reichert Young ultramicrotome. The sections are placed on a copper grid (200 Mesh). Sections were coated with a conductive layer of carbon in a sputter coater to avoid charging effects.

The sections were studied with a Scanning Transmission Electron Microscope (Philips CM30) operating at a voltage of $100 \mathrm{kV}$. The microscope is fitted with an energy dispersive X-ray spectrometer (EDAX $30 \mathrm{~mm}^{2} \mathrm{Si}(\mathrm{Li}) \mathrm{R}$-SUTW detector). Elemental profiles from the centre to the periphery of the particles were performed using Energy Dispersive X-ray 
spectrometry (EDXS). The concentration profiles were made across three different particles. The elemental composition was determined by using the Cliff and Lorimer method ${ }^{11}$. The calibration procedure was performed with standards. Concentrations are expressed in mmol. $\mathrm{kg}^{-1}$ of resin embedded material.

\section{Results}

Concentrations gradients of $\mathrm{Ca}, \mathrm{P}, \mathrm{Al}$ and $\mathrm{Si}$ across the periphery of bioactive glass particles were studied by electron probe X-ray microanalysis on thin sections. Elemental profiles for different exposure times to biological solution revealed different zones from the centre to the periphery of the bioactive glass particles (figures 1-5).

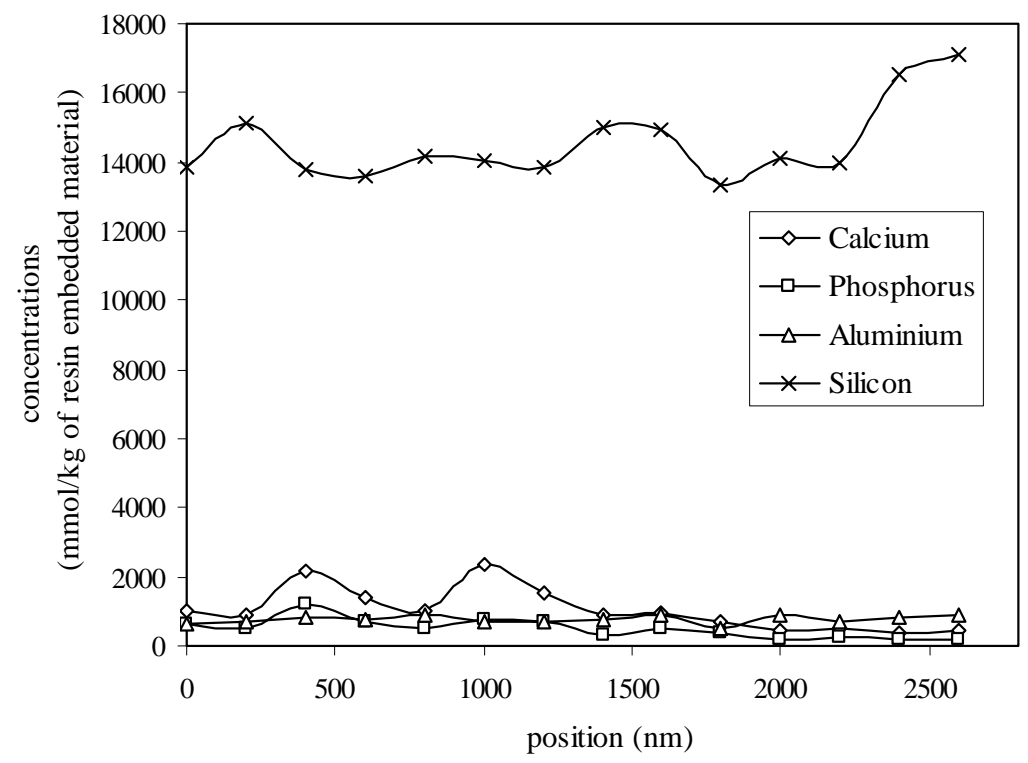

Figure 1 : Ca, P, Al and Si concentrations (mmol. $\mathrm{kg}^{-1}$ of resin embedded material) profiles across the periphery of bioactive glass particles at 1 day after immersion in a standard culture medium. 
After 1 day of immersion into biological fluids, the bioactive glass particles periphery are essentially composed with $\mathrm{Si}, \mathrm{Ca}, \mathrm{P}$ and $\mathrm{Al}$ (figure 1). After 2 days, Ca and $\mathrm{P}$ decreases and a pure $\mathrm{Si}$-Al layer is formed (figure 2). On top of this $\mathrm{Si}$-Al layer, we observe an increase of $\mathrm{Ca}$ and $\mathrm{P}$ concentrations with a $\mathrm{Ca} / \mathrm{P}$ atomic ratio near unity. A Ca-P layer appears at the periphery of biological particles.

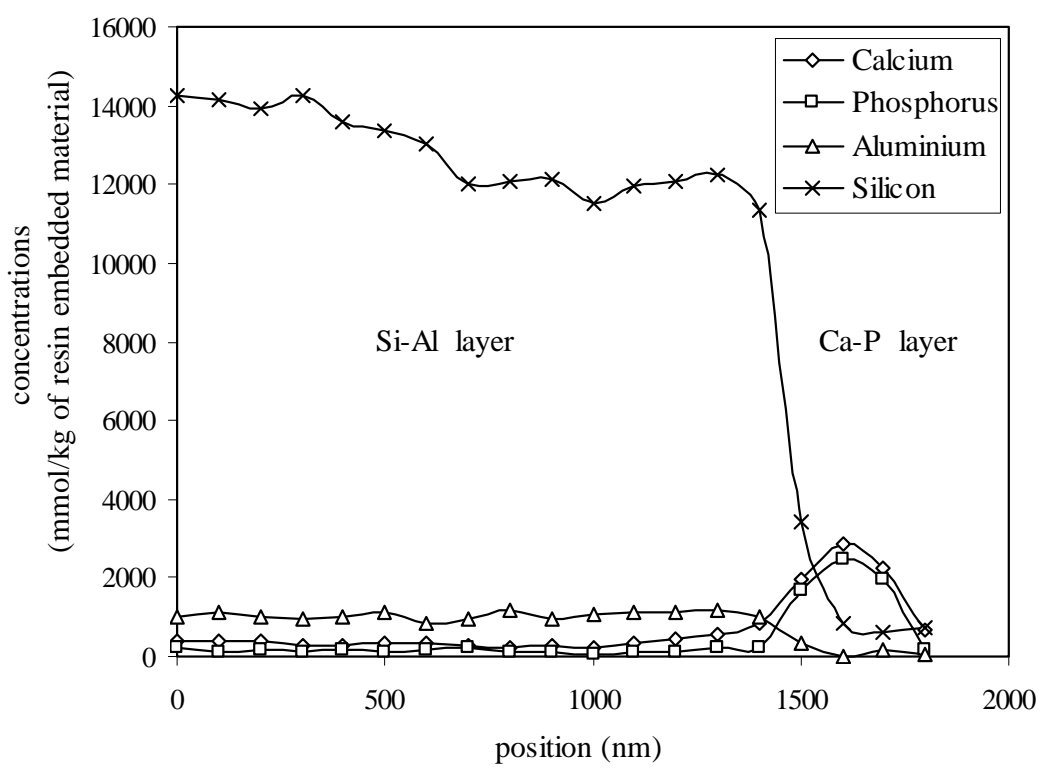

Figure 2 : Ca, P, Al and Si concentrations (mmol. $\mathrm{kg}^{-1}$ of resin embedded material) profiles across the periphery of bioactive glass particles at 2 days after immersion in a standard culture medium.

After 4 days of immersion into biological fluids, the bioactive glass is still in dissolution and releases $\mathrm{Ca}, \mathrm{P}, \mathrm{Si}$ and $\mathrm{Al}$ ions. On figure 3, STEM micrograph shows a particle in dissolution with the formation of a Ca-P layer at its periphery. The concentrations of $\mathrm{Ca}, \mathrm{P}$ continue to increase in the Ca-P layer and the $\mathrm{Ca} / \mathrm{P}$ atomic ratio is now of the order of 1.4 (figure 4). 


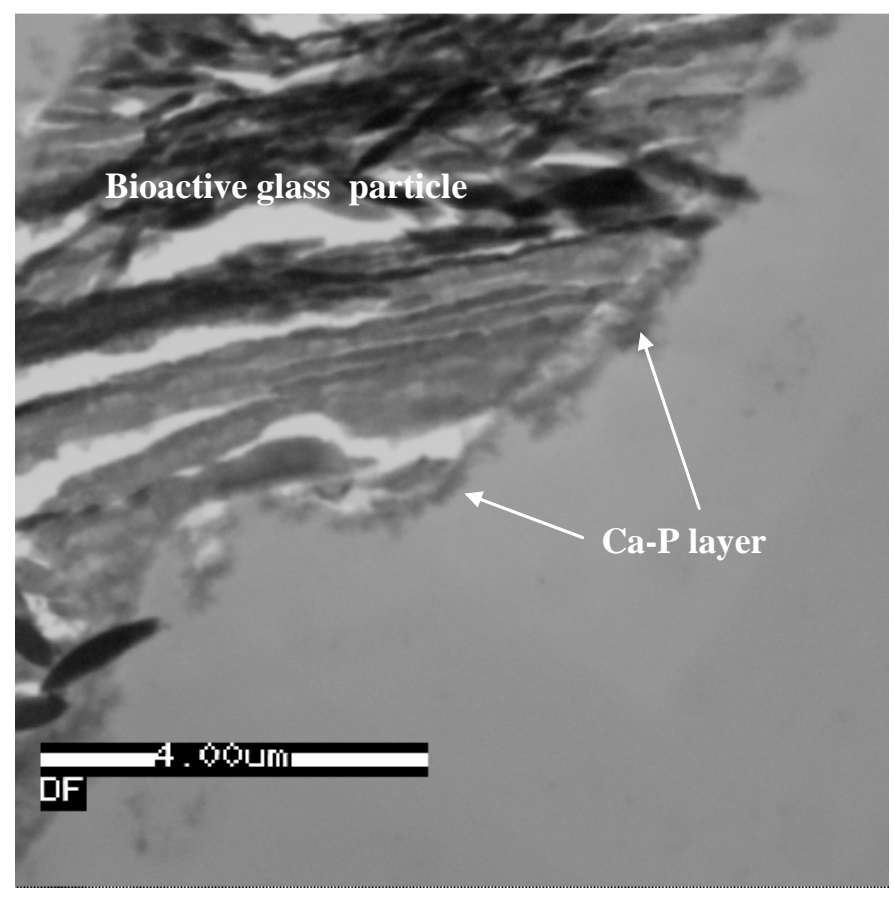

Figure 3 : STEM micrograph of a bioactive glass particle periphery at 4 days after immersion in a standard culture medium.

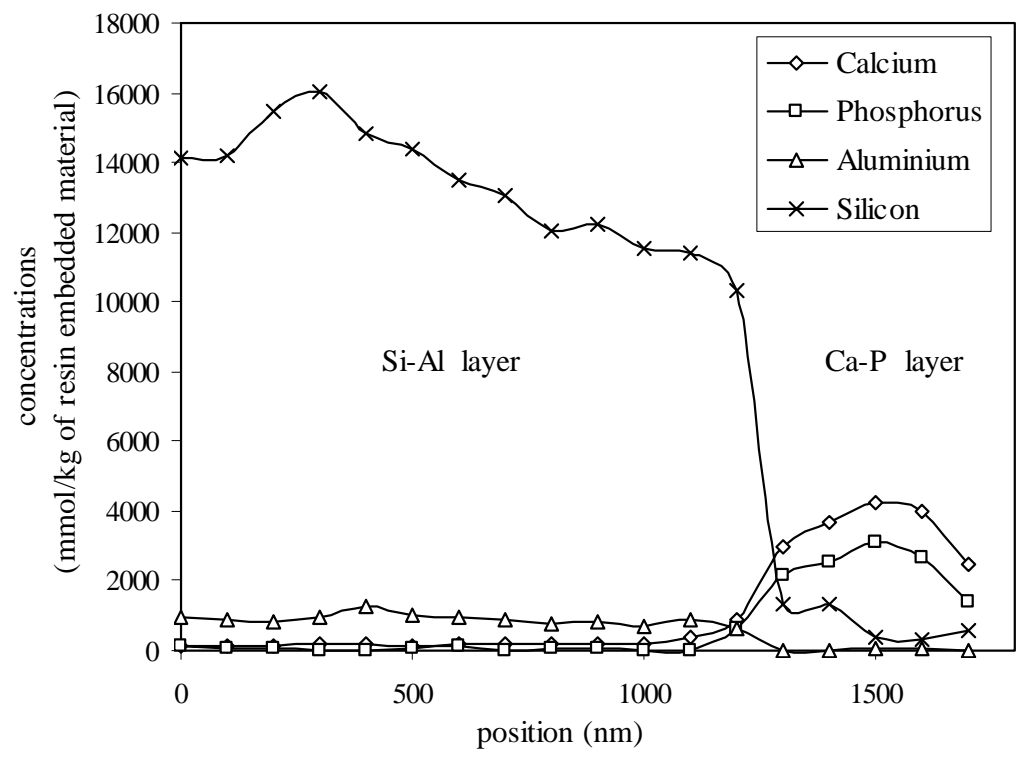

Figure 4 : Ca, P, $\mathrm{Al}$ and Si concentrations (mmol. $\mathrm{kg}^{-1}$ of resin embedded material) profiles across the periphery of bioactive glass particles at 4 days after immersion in a standard culture medium. 
After 28 days of immersion into biological fluids, the bioactive glass periphery is composed with a Si-Al layer and a Ca-P layer (figure 5). The $\mathrm{Ca} / \mathrm{P}$ atomic ratio in the $\mathrm{Ca}-\mathrm{P}$ layer is of the order of 1.6. The size of this layer increases with time after exposure to the solution and is now of the order of some micrometers.

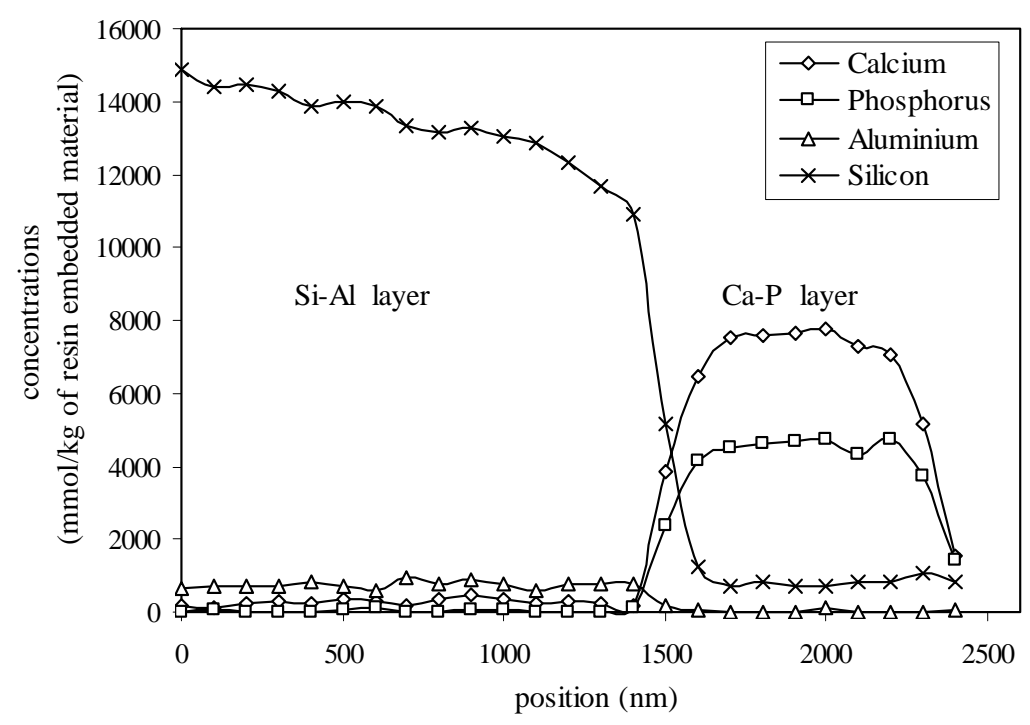

Figure 5 : Ca, $\mathrm{P}, \mathrm{Al}$ and $\mathrm{Si}$ concentrations (mmol. $\mathrm{kg}^{-1}$ of resin embedded material) profiles across the periphery of bioactive glass particles at 28 days after immersion in a standard culture medium.

\section{Discussion}

The present work analyzes the periphery changes of bioactive glass particles immersed into biological fluid. A physico-chemical approach is adopted, namely the analysis of the transformation kinetics of the glass composition by means of EDXS to understand mechanisms of interaction.

As the glass matrix dissolves, various elements dispersed in the bioactive glass are free to go either into the solution or to combine with elements in the bioactive glass that make up surface layers. The distribution of calcium, phosphorus, silicon and aluminium differs 
between the glass particles centre and the newly formed layers at the periphery. Formation of these layers include a complex series of physico-chemical and ultrastructural phenomena. After 1 day of immersion into biological fluids, the bioactive glass particles are in dissolution and $\mathrm{Si}, \mathrm{Ca}, \mathrm{P}, \mathrm{Na}, \mathrm{K}, \mathrm{Mg}, \mathrm{Al}$ are released. $\mathrm{Na}^{+}$and $\mathrm{K}^{+}$ions are rapidly and highly released. An appreciable amount of $\mathrm{Si}, \mathrm{Ca}, \mathrm{P}, \mathrm{Mg}$ ion is, however, released from the bioactive glass into the surrounding fluids. $\mathrm{Al}$ is released more slowly. The dissolution results from breaking of Si-O-Si bonds. This dissolution leads to the formation of a Si-Al rich layer on the surface. Then, this Si-Al layer permits the diffusion of Ca and P elements. After 2 days of immersion into biological fluids, an accumulation of $\mathrm{Ca}^{2+}, \mathrm{PO}_{4}{ }^{3-}$ ions occurs on top of this layer and a Ca-P rich layer start to build up. This Ca-P layer evolves with time of exposure to biological solution. The $\mathrm{Ca} / \mathrm{P}$ atomic ratio in the calcium phosphate layer increases from 1 to 1.6. The size of this layer increases and after 28 days its size is of some micrometers.

These variations reflect the formation and the growth of an apatite layer at the bioactive glass periphery. Growth of the amorphous Ca-P rich film is by incorporation of soluble calcium phosphates. The calcium ions might increase the degree of supersaturation of the surrounding body fluid and cause precipitation. The precipitation conditions favour the formation of bone apatite like crystals. However, apatite nucleation can be triggered with the presence of the silica gel like layer. Clark A.E. and Hench L.L. ${ }^{12}$ proposed that layer formed by condensation of silanol bonds are responsible for the nucleation of apatite. Apatite formation on the surface of materials is a material-dependent and mainly chemical phenomenon. The bioactive surface of the bioactive glass implant serves as a template for amorphous apatite precipitation from surrounding fluids. Formation of this apatite layer represents bioactivity properties of bioactive glasses. In vivo, this layer will permits the creation of an interfacial bonding zone between bone tissues and the implanted materials ${ }^{13}$. 


\section{Conclusion}

In case of bioactive glasses that undergo dissolution due to ion diffusion, spatially resolved X-ray microanalyses is of great importance in evaluating mechanisms of physicochemical reactions between material and biological fluids, because the phenomenon occurs under micrometer scale. These reactions can be decomposed in ion leaching, partial dissolution of the glass-surface and physico-chemical reactions which lead to the formation of a silicon-aluminium rich layer and precipitation of a bone like apatite layer on the glass surface. Formation of the apatite layer represents bioactivity properties of the studied bioactive glass. Presence of $2 \% \mathrm{Al}_{2} \mathrm{O}_{3}$ in the bioactive glass reduces its dissolution but do not inhibit its bioactivity. 


\section{References}

1 - Jallot E., Irigaray J.L., Weber G.,Frayssinet P. In vivo characterisation of the interface between cortical bone and biphasic calcium phosphate by P.I.X.E. method. Surf. Interface Anal. 27 (1999) 648.

2 - Hench L.L, Splinter R.J., Greenlee T.K., Allen W.C. Bonding mechanism at the interface of ceramic prosthetic materials. J. Biomed. Mater. Res. 5-2 (1971) 117.

3 - Neo M., Nakamura T., Kikutani T., Kawanabe K., Kokubo T. Apatite formation on three kinds of bioactive material at an early stage in vivo:Acomparative study by transmission electron microscopy. J. of Biomed. Mater. Res. 27 (1993) 999.

4 - Ohtsuki C., Kokubo T., Yamamuro T. Apatite formation induced by silica gel in a simulated body fluid. J. Am. Ceram. Soc. 75 (1992) 2094.

5 - Ohtsuki C., Kokubo T., Yamamuro T. Mechanism of apatite formation on CaO-SiO $2-\mathrm{P}_{2} \mathrm{O}_{5}$ glasses in simulated body fluid. J. Non-cryst. Solids 143 (1992) 84.

6 - Hench L.L. Bioceramics: from concept to clinic. J. Am. Ceram. Soc. 74 (1991) 1487.

7 - Kangasniemi K., Yli-Urpo A. Biological response to glasses in the $\mathrm{SiO}_{2}-\mathrm{Na}_{2} \mathrm{O}-\mathrm{CaO}-\mathrm{P}_{2} \mathrm{O}_{5}-$ $\mathrm{B}_{2} \mathrm{O}_{3}-\mathrm{Al}_{2} \mathrm{O}_{3}$ system. Wilson, J., eds. CRC Handbook of Bioactive Ceramics, Vol. 1, Bioactive Glasses and Glass-Ceramics: Boston :CRC Press, 97 (1990).

8 - Andersson O.H., Liu G., Karlsson K.H., Niemi L., Miettinen J., Juhanoja J. In vivo behaviour of glasses in the $\mathrm{SiO}_{2}-\mathrm{Na}_{2} \mathrm{O}-\mathrm{CaO}-\mathrm{P}_{2} \mathrm{O}_{5}-\mathrm{Al}_{2} \mathrm{O}_{3}-\mathrm{B}_{2} \mathrm{O}_{3}$ system. J. Mater. Sci. Mater. Med. 1 (1990) 219.

9 - Andersson O.H., Karlsson K.H. Development of bioactive glasses and glass-ceramics. Wilson, J., eds. CRC Handbook of Bioactive Ceramics, Vol. 1, Bioactive Glasses and GlassCeramics: Boston :CRC Press 143 (1990).

10 - Jallot, E. ; Benhayoune, H. ; Kilian, L. ; Josset, Y. ; Balossier, G. An original method to assess short-term physico-chemical reactions at the periphery of bioactive glass particles into 
biological fluids. Langmuir 17 (2001) 4467.

11 - Cliff G., Lorimer G.W. The quantitative analysis of thin specimens. J. Microsc. 103 (1975) 203-207.

12 - Clark A.E., Hench L.L., Kim C.Y. Compositional dependence of calcium phosphate layer formation in fluoride Bioglass ${ }^{\circledR}$. J. Biomed. Mater. Res. 26 (1992) 1147.

13 - Jallot E., Benhayoune H., Kilian L., Irigaray J.L., Barbotteau Y., Balossier G., Bonhomme P. Dissolution kinetics, selective leaching and interfacial reactions of a bioglass coating enriched in alumina. Journal of Colloid and Interface Science 233 (2001) 83. 